\title{
Lesson Study: A Collaborative Process for Advancing Mathematics Teaching and Learning
}

\author{
Cathy Kinzer \\ New Mexico State \\ University
}

\author{
Kathryn Million \\ Chris Woods \\ Las Cruces Public Schools
}

\author{
Helen Duran \\ Gadsden Independent \\ School District
}

\author{
Cynthia Bond \\ Alamogordo \\ Public Schools
}

\begin{abstract}
Lesson Study is a classroom-based process used in education for studying and improving lessons to support students' learning. The Lesson Study cycle has the potential for building shared professional knowledge about mathematics and improving instructional practices. It can influence teaching and students' mathematics experiences through designing, implementing, and determining the impact of research lessons taught in mathematics classrooms. The premise is that, if mathematicians, mathematics educators, and teacher leaders design and implement robust research lessons in $K-12$ classrooms, the Lesson Study process can serve as a mechanism for actively examining classroom instructional practices and understanding their relationships to students' mathematics learning. If schools want classrooms where students are engaged in understanding and making sense of mathematics, then teachers also need to engage in professional experiences that build content knowledge and pedagogical approaches for effective mathematics instruction. This article presents an overview of the Leadership Institute for Teachers (LIFT) research project and a theoretical framework for this approach to professional learning. It includes data from classroom observations and teacher leaders' comments to document their perceptions and their insights of Lesson Study conducted in mathematics classrooms.
\end{abstract}

\section{Introduction}

The purpose of this article is to document teacher leaders' learning as a result of participating in Lesson Study in a university and K-12 mathematics research project. The Leadership Institute for Teachers (LIFT) is a National Science Foundationfunded mathematics project (\#0928867) for two cohorts of $30 \mathrm{~K}-12$ teachers who are becoming teacher leaders by engaging in rigorous coursework at a university (New Mexico State University) and implementing their learning at their respective school sites. The research project utilizes a variety of data to understand (a) how to advance $\mathrm{K}-12$ students' mathematics learning and achievement, (b) how to design and implement relevant coursework at the university that influences $\mathrm{K}-12$ classroom instruction, and (c) how professional learning experiences for teacher leaders develop effective mathematics teaching and school-based mathematics leading. The LIFT researchers utilized several sources of data, including documentation of teachers' instructional practices through classroom observations, mathematical knowledge assessments for LIFT teacher leaders, and students' achievement data on standardized tests to determine the impact of the project on teaching and learning.

The LIFT project includes six semesters of mathematics and education courses that are collaboratively designed and taught by mathematics educators and mathematicians. The project includes ongoing opportunities to connect the university coursework to teacher leader classrooms to study and improve mathematics teaching. As a research project, LIFT is exploring how $\mathrm{K}-12$ teachers in the cohort change their instructional practices as a result of engaging in the coursework and related schoolbased activities.

One of the approaches for connecting LIFT university mathematics and math education courses and $\mathrm{K}-12$ classrooms is through Lesson Study. Lesson Study includes many elements of effective professional development, such as developing authentic useful knowledge and skills within a classroom setting, engaging in collaborative coaching, and developing content and pedagogical content knowledge for teaching [1] [2] [3] [7]. The coursework includes a requirement that teacher leaders in the cohort engage in two cycles of collaborative Lesson Study. LIFT researchers were curious to know whether Lesson Study would affect mathematics teaching in LIFT teacher leaders' classrooms.

In the Lesson Study process, LIFT teacher leaders use classroom data to develop learning goals for students. They collectively design, teach, and study their research lessons and analyze the resultant students' learning. Based on observational data gathered by the Lesson Study team, videos of the lessons, and the students' artifacts, the research lessons are redesigned and taught for further study of instruction, content understandings, students' engagement and their mathematics strategies.

Participating in Lesson Study over time has the potential for building shared professional knowledge about mathematics and developing responsible 
instructional practices. The premise is that, if mathematicians, mathematics educators, and LIFT teacher leaders design and implement research lessons in K-12 classrooms, the Lesson Study process can serve as a mechanism for actively examining classroom teaching practices and understanding their relationships to students' mathematics learning.

This article presents an overview of the LIFT research project and a theoretical framework for a Lesson Study approach to professional learning. It includes data from classroom observations and teacher leaders' comments to document their perceptions and insights about the Lesson Study process.

\section{LIFT research project: Context}

LIFT connects and engages educators and administrators from elementary, secondary, and university settings in a research project that studies mathematics teaching and learning in order to improve what happens daily in mathematics classrooms for K-12 students. LIFT project goals are (a) increasing teacher leaders' knowledge, skills, and dispositions through blended courses focused on teaching $\mathrm{K}-12$ mathematics that incorporate responsible pedagogical practices; (b) developing intellectual leaders who ensure effective mathematics learning and who can differentiate instruction in their own classrooms and support other teachers to meet the needs of diverse learners; (c) implementing LIFT learning in mathematics classrooms and schools with mentoring from the LIFT school support team; and (d) building and sustaining viable partnerships based on shared goals for learning by mathematicians, education faculty, and educators in school districts.

LIFT focuses on mathematics education leadership in $\mathrm{K}-12$ schools. Teacher leaders in the project develop content and leadership knowledge through 33 hours of university coursework required to obtain a Master of Arts in Teaching Mathematics degree. The LIFT cohort includes teacher leaders from five school districts representing a broad array of knowledge, skills, and experiences. LIFT educators open their classrooms as a space for building shared professional knowledge and developing teaching skills, and they collaborate with teachers at their respective campuses. LIFT utilizes course experiences and assignments applicable in teacher leader classrooms as a vehicle to develop mathematics content, pedagogical content knowledge [4] [5] [6] [7] and pedagogy, with the ultimate goal of supporting mathematics learning for $\mathrm{K}-12$ students.

As classroom teachers encounter increasing expectations for gains in their students' mathematics achievement, the LIFT university coursework is a way for collectively studying instructional routines and actions within mathematics learning environments. LIFT course designers and teacher leaders consider how to improve mathematics instruction both at the university and in the K-12 LIFT classrooms through utilizing research-based practices and studying their impact on learning.

The LIFT research project investigates the effectiveness of project coursework utilizing a mixed-methods methodology [8] [9]. This design supports collection and analysis of quantitative and qualitative data related to teacher leader learning of mathematics, pedagogy, and leadership. Data are continuously analyzed regarding teacher leader participation in LIFT, students' mathematics achievement, and the development of effective classroom learning environments [10]. Data sources include focus groups/interviews, pretest/ posttest mathematics and pedagogical content knowledge assessment, pre/post classroom observations each semester, teacher and administrator surveys, and formative and summative feedback. These data are used to understand the learning needs of the teacher leaders in the LIFT cohort. The iterative cycles of gathering and analyzing both formal and informal assessment data in the $\mathrm{K}-12$ classrooms and university coursework appraises ongoing LIFT course design and the next steps for school-based support; this process is used to guide the research project holistically.

A central goal in LIFT coursework is to advance mathematics learning for all students. This goal is achieved by building useful content knowledge and developing problems and activities within a learning progression of mathematics concepts that are applicable in $\mathrm{K}-12$ classrooms. LIFT courses create a culture for dialogue, modeling, experimenting, and reconceptualizing mathematics as a content domain and space for developing and studying instructional strategies and practices. Coursework provides opportunities to continue to learn mathematics for oneself, as well as to study how to facilitate mathematics learning for others [11]. The university courses are collaboratively designed and taught by mathematics educators and mathematician teams to connect mathematics and pedagogy. The university course experiences are designed for learning mathematics in ways that reflect what might be experienced in robust $\mathrm{K}-12$ mathematics classrooms.

\section{Linking research and practice through the Lesson Study approach}

Project researchers and course developers aim to determine whether university coursework influences teachers' perceptions about teaching mathematics, the classroom instructional practices, and students' learning and, if so, in what ways. Each LIFT teacher leader is observed in the classroom during the two years in the cohort, at the beginning and end of each semester, while teaching mathematics. Observational data and teacher leader feedback for the second 
cohort in the project indicated a need for professional learning experiences situated in mathematics classrooms with colleagues through a Lesson Study approach. Lesson Study has the potential to provide a classroom-based opportunity for serious study of mathematics instruction by educators, mathematicians, and mathematics educators in LIFT. For many LIFT cohort members, it opens new pathways for sharing teaching practices in situ and for team planning, teaching and revising research lessons with an eye on students' mathematical thinking.

\section{Theoretical framework for LIFT Lesson Study}

\subsection{Developing the dispositions, skills, and knowledge for studying teaching practices in classrooms}

Teaching is a cultural activity that inherently includes a substantial level of resistance to change; however, effective teaching is crucial to improving students' mathematics learning [12] [13] [14] [15]. Research on educational improvement indicates a need for professional learning experiences that provide ongoing opportunities to examine beliefs, ingrained assumptions, and thinking about what it means to teach mathematics [16] [17] [18]. To change teaching itself requires effort, time, and opportunities to examine one's identity as a teacher, beliefs about intelligence and instruction, sense of efficacy, and understanding students' roles and ways of participating as learners. Through meaningful collaborative work, teachers have the opportunity to confront their beliefs, perceptions, and mindsets about mathematics teaching [19]. Building relational trust with colleagues and demonstrating a willingness to be vulnerable in sharing one's practices and ideas with colleagues are attributes of a professional learning stance. Utilizing teaching and learning cycles in Lesson Study provides a mechanism to study actions or practices within teaching itself and is a plausible strategy in considering how teaching hinders or supports students' mathematics learning [12] [13] [33].

\subsection{Practice-based professional learning}

Collaboratively developing the knowledge needed for effective mathematics teaching is an essential investment for educators [11] [14] [15] [31]. Professional learning situated in classrooms provides a viable avenue for understanding the complexities of a well-designed lesson in relation to teaching practices and students' learning [20] [21] [23] [33]. Professionals in many fields, such as doctors and lawyers, have processes and procedures for continuing to learn and improve their craft in situ. Through this approach, they develop useful knowledge, skills, and practices within the work context and minimize the knowing-doing gap [28] [29]. In Lesson Study, teachers engage in collective inquiry, problem solving, discourse, and doing mathematics in a classroom-learning environment [32] [33] [34].

Mathematics teaching and learning can be studied through more traditional venues such as courses and workshops or in collaborative practice-based experiences within classrooms. These situated learning experiences can be useful in developing knowledge of mathematics and studying and refining instructional practices that support students' understanding and sense making in mathematics [11]. Transformative models of professional learning for teachers should be (a) embedded in or directly related to the work of teaching, (b) grounded in the mathematics content, (c) developed through communities of practice, (e) sustained in collaboration with "knowledgeable others" outside the teaching community, and (f) focused on equitable student learning [17] [32] [33]. Teachers with a shared commitment to instructional improvement can utilize a purposeful learning community to unpack and rehearse the complex tasks within teaching [2] [12] [21] [22] [23] [24]. Professional communities offer a structure for improving teaching through utilizing shared norms and goals, developing/refining explicit skills and routines in mathematics lessons, and using inquiry research processes to improve teaching practices [25] [26] [27].

These practice-based professional learning opportunities should occur over time; produce knowledge, skills, and dispositions for learning; and develop a reflective stance for collective inquiry and continuous improvement of teaching [17]. Developing this disposition of inquiry is a challenge that teachers face when examining their practice [5]. To improve practice, teachers must learn in and from their practice both the subject matter and how to teach the subject effectively to culturally and linguistically diverse students. Through systematic use of collaborative inquiry, analysis, and reflection on teaching and learning, teachers can develop "knowledge of practice" and utilize a growth mindset that embraces learning as a process to improve instruction over time [11] [19] [25].

\subsection{Professional knowledge for teaching}

If teachers are to teach mathematics for deeper understanding through pedagogical approaches that are engaging to students, the professional learning should mirror the type of instruction that schools would like to see practiced in the classroom [5] [30] [31]. Effective teaching requires extensive knowledge, skills, and deliberate practices or actions such as connecting to learners' prior knowledge and experience, developing coherent structures of related 
knowledge rather than isolated bits of information, engaging students in problem solving and inquiry, and explicitly validating mathematical ideas and strategies [11] [26] [30]. This requires a deep and useful understanding of the structure of mathematics concepts and the strategies that students use in learning mathematics, the conceptions and ideas that students may generate, where students might struggle or have misconceptions, and how to respond appropriately to students' thinking and ways of communicating their ideas [6] [11] [26] [30].

High-leverage teaching practices such as posing worthwhile problems or tasks and understanding how to differentiate instruction in order to develop students' thinking and problem-solving skills are integral to responsible mathematics teaching [11] [30]. Teaching requires being cognizant of students' responses to teaching actions and how students engage in learning processes. Teaching, particularly in mathematics, is complex and requires generative professional opportunities to understand the relationships among research, teaching, and students' learning.

\subsection{The Lesson Study process}

Lesson Study in mathematics is a collaborative inquiry-based process to consider an area of difficulty or interest for focused learning [24] [33]. This reflective process conducted in classrooms can serve as a way to build professional knowledge for teaching, as teachers are the practitioners and researchers. In Lesson Study, educators develop overarching, unit, and lesson goals for students' learning of the concept. Based on these goals, the Lesson Study team investigates the mathematics of the lesson, considers possible strategies and approaches to the mathematics task, and considers the flow of the lesson [33]. The mathematics lesson is taught by a team member, observed for students' interactions and learning, and then discussed based on lesson goals and the resultant learning. The research lesson is then revised through reflection and thoughtful improvement for reteaching [32] [33] [34]. Students' thinking, learning processes, and strategies for solving problems are the central focus of the research lessons. Teachers scrutinize the possible strategies involved in the task through longitudinal exploration of important mathematical concepts, thereby promoting their own content understanding, development of skillful teaching, and building a shared professional knowledge base [20] [28] [31]. The Lesson Study process promotes actual study of teaching itself, with the goal of steady improvement in mathematics learning by students [14]. Lesson Study is a process for developing practitioners' knowledge that is situated in classroom learning.

\subsection{LIFT Lesson Study implementation}

After two semesters of LIFT coursework, the faculty introduced teacher leaders to the Lesson Study research process. The teachers were presented an overview and a video of a lesson study. Lesson Study goals were discussed and the lesson plan template that would assist in designing a research lesson was provided to teacher leaders by faculty. The LIFT teacher leaders utilized common protocols for observing during the research lesson, engaging in the Lesson Study cycle, and reporting and preparing presentations for LIFT faculty and colleagues in the cohort. These protocols were research based and had been designed and utilized by LIFT faculty in prior Lesson Study work [24]. Teacher leaders formed teams by grade bands $(\mathrm{K}-1,2-3,4-6,7-8$, and high school), with three to five teacher leaders in each band, to determine their collective focus, design research lessons, and engage in the Lesson Study process with mathematicians and mathematics educators.

For two semesters, or four cycles of Lesson Study (design, teach, redesign based on data, and teach), teacher leaders worked with university faculty in collaborative research via Lesson Study to think about lesson design, instructional moves, students' engagement, and learning through the mathematics lesson. Teacher leaders did not know who would teach the mathematics research lesson until a name was drawn on the day that the lesson was to be taught. This built a collective responsibility and shared knowledge about the research lesson. The lessons were videotaped; then approximately 3 hours were spent in studying the video, engaging in discussions, determining lesson revisions, and thinking deeply about the teacher's and students' actions.

Teacher leaders utilized classroom data to make instructional decisions within the Lesson Study process. From a project perspective, LIFT was interested in knowing how the Lesson Study experiences might influence each cohort member's mathematics teaching and their students' learning and participation in mathematics.

\section{Research data on LIFT teacher leader mathematics classrooms}

\subsection{Observational data}

The LIFT teacher leaders were observed while teaching mathematics in order to understand how the learning from the coursework and the related project experiences, such as Lesson Study, were applied in classroom practices. Observations were completed by trained observers utilizing the Observation of Learning Environments (OLE2) instrument, which is designed specifically for mathematics classrooms. A 
well-developed teacher observation instrument and well-prepared observers can provide feedback to teachers regarding teaching [35]. The instrument includes five major indicators with descriptors. Each indicator is aligned to a scale of 0 (non-use) to 4 (advanced), with classroom "look fors" to document observable actions related to each indicator.

The OLE2 instrument is research based and denotes elements of an effective mathematics learning environment that ranges from teacher didactic instruction to students' active engagement in rigorous mathematics, including connections with Common Core State Standards (CCSS) mathematical practice standards [36]. Observations usually lasted for an hour and included both lesson scripting and classroom data related to the observation instrument indicators.

Each of the 29 teacher leaders in the second LIFT cohort were observed in their classrooms using the OLE2 eight times: once in spring 2012, twice in fall 2012, twice in spring 2013, twice in fall 2013, and once in spring 2014. Most of these observations were unscheduled and LIFT teacher leaders did not know when the observer would visit the class. The observations were nonevaluative; rather, the instrument was utilized to gather quantitative and qualitative data regarding mathematics teaching and learning in a lesson. The research goal was to document changes in the LIFT cohort members' teaching practices.

After two full years of LIFT, the OLE2 data for this cohort revealed that implementation of an effective mathematics learning environment was much more evident in LIFT K-12 classrooms than in other classrooms. Seventy-two percent of the teacher leaders (21/29 participants) routinely scored 3 (proficient) or 4 (advanced) in implementation of an effective mathematics-learning environment [37]. All five indicators on the OLE2 increased for the cohort from spring 2012 to spring 2014.

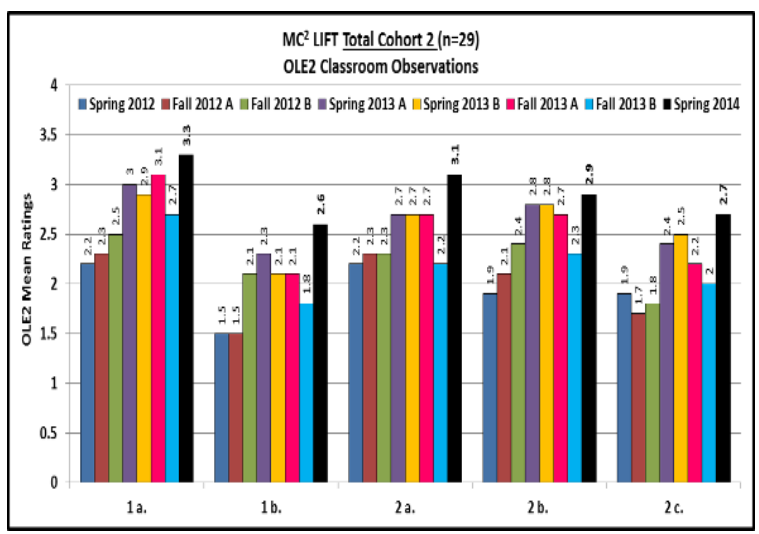

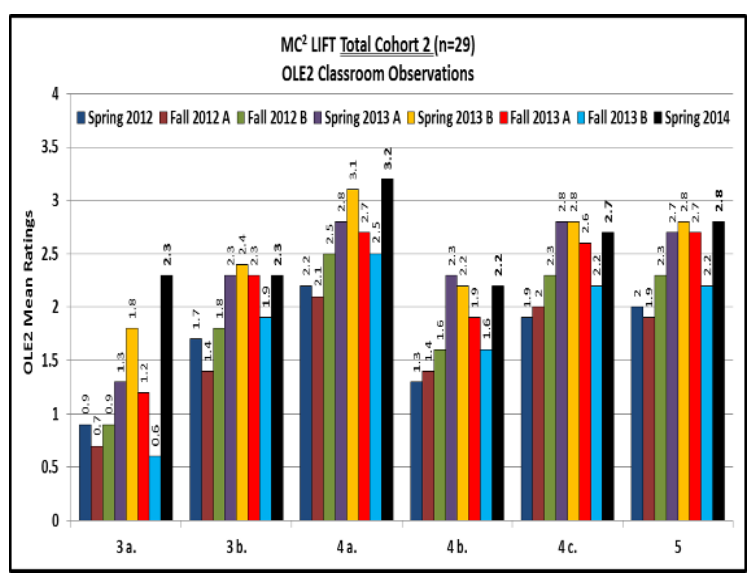

\subsection{Teacher leaders' perceptions of Lesson Study}

LIFT teacher leaders and researchers documented the Lesson Study experience. LIFT teacher leaders constructed lesson study reports that represented their learning experiences. These reports included an overview of the Lesson Study process, mathematics learning, and instructional strategies. Teacher leaders also addressed these questions:

1. As a mathematics team, how has your involvement in the Lesson Study process impacted the way you work with other teachers at your school?

2. Personally, how did Lesson Study support your growth as a teacher?

3. What are the strengths and weaknesses of the Lesson Study process? In what general ways can the Lesson Study process be improved? How can the Lesson Study process be adapted to better fit within your school context?

Selected LIFT teacher leader comments from their record of Lesson Study are presented in this section. Each LIFT teacher leader comment is denoted by TLC\# at the conclusion of the statement.

Lesson Study allowed for a very conscious effort in understanding exactly what was being done during the lesson, why it was being done, what student misconceptions about the math that teachers needed to be prepared for, and what accommodations might need to be made for certain students. During the reflection and discourse with colleagues, tremendous learning occurred from the sharing of insights and knowledge. As a result, the students received a much richer and deeper experience of learning in the subsequent math lesson. (TLC\#1)

Many students in the Lesson Study classrooms are English Learners. Teachers had the opportunity to design lessons that considered the cognitive demands of tasks as well as the language and content demands. They listened to students' thinking and observed ways in which they were engaging in mathematics. 
Lesson Study influenced classroom instruction by helping me to realize that teacher collaboration and student achievement are closely connected and that the continuous cycle of pedagogical refinement is crucial. The implementation of formative assessment, data analysis, peer teacher observations with collaborative analysis, are all a part of continuous inquiry and improvement for student learning. In addition, I saw firsthand the positive impact a "student responsive" learning environment has on ELs [English Learners] and students that have less confidence in their math thinking as it brings a tangible element of equity for all learners. (TLC\#2)

The research lessons provided the opportunity to consider potential sequences of concepts, teacher instructional moves, manipulative uses, learning goals, what questions were asked, and how those choices affected students' thinking and learning. Teacher leaders engaged in the mathematics of the research lesson to identify possible strategies and misconceptions that students have or might have regarding mathematics. Educators and mathematicians thinking collectively about possible student misconceptions provide a deeper discussion of the mathematics concepts and problem-solving strategies. It takes time and knowledge to develop a research lesson, teach the lesson, and redesign the lesson based on students' learning. LIFT teacher leaders valued the focused time for collaborative classroom-based professional learning.

It was very useful to take a standard and really study it in depth and have time to think about all the aspects of it and misconceptions students might have. It changed how I look at mathematics standards and how I should understand them before teaching them. I really think about not just the learning targets, but misconceptions, vocabulary, equity, assessments, and so much more! One insight was the importance of the language that teachers used in describing the learning target and steps in the lesson on how the students carried out the lesson. As I'm writing this, I realize how obvious this will sound to an outsider, but students catch on to phrases that will either support and further their understanding or confuse them. I now understand the importance of supporting students' development of math and language through speaking, listening, reading and writing. (TLC\#3) Study:

An elementary teacher leader reflected on Lesson

I have learned so much through the Lesson Study process. My eyes were really opened as to how important it is to understand the vocabulary in the math standards so that I know exactly what I am teaching and what my students need to be learning. I also learned the value and benefit of collaborating with a team to see different perspectives and learn from each other. All the insights and ideas shared throughout Lesson Study have added to my knowl- edge base as a teacher. I have come to understand how much can be learned from a well-planned, -researched, and -thought-out lesson. My learning from Lesson Study helped me in the classroom with math standards and gave me insights into student groupings and interactions, as well as ideas on addressing student misconceptions, and providing challenging yet accessible tasks. (TLC\#4)

A central goal of the LIFT project is to develop the teacher's mathematics content and pedagogy. Lesson Study teams had opportunities to deepen their mathematical knowledge through planning conversations and designing and teaching the research lessons in their classrooms.

The big goal of our lesson was decomposing numbers from 1 to 10 into pairs. One of the insights for me was making sure I really understood the vocabulary. After our morning lesson we realized that the students were composing, "3 and 2 make 5" or " 4 and 1 is a combination of 5 " instead of decomposing " 5 can be broken/decomposed into 3 and 2." We modified our vocabulary and the way we introduced decomposing in the afternoon, as well as the recording sheet $(5=3+2)$. By using several strategies for decomposing, it reached students at different levels. In our first lesson students counted the dots on dominoes by ones. In the afternoon we focused on seeing patterns of dots and knowing the amount"See it and say it" (subitizing)—as well as counting. As a result, we saw more students using these strategies to find the total amount of dots on the dominoes. (TLC\#5)

A teacher leader on a K-1 lesson study team began to understand the difference between the "semantic form" of an equation and the "computational form," as noted below:

Our word problem was "Ida gives out 8 milks to students in our class. Then, Maria Elena gave out some more. Our class now has 12 milks. How many milks did Maria Elena give out?" The correct semantic equation would be to follow the word problem as $8+?=12$. The computational form to solve the problem could be the same as the semantic or it could be computed as $12-8=$ ? Therefore, the act of computing the problem changes the semantic meaning of the problem. This ability to switch between computation and semantic demonstrates a flexibility of number relationship, but ultimately the child needs to be able to put their reason back into the semantic form of the word problem. (TLC\#6)

The teacher leaders study mathematics and pedagogy in the LIFT courses through mathematics learning progressions, with, for example, the mathematics ideas leading to the distributive property and how the property is applied in elementary grades to secondary courses. This learning progression indicates key mathematics ideas that a student would encounter in developing mathematics 
concepts over time and is used in designing research lessons for diverse learners and multigrade teams.

We engaged students' interest and attention to learning by facilitating and soliciting active participation and creating a student-centered learning environment in which students were exploring, creating, sharing their mathematical thinking, creating viable arguments and critiquing the reasoning of others, taking notice of repeated patterns, questioning, presenting, connecting to real-world scenarios, and formative assessment/progress monitoring. As a result of this Lesson Study specific to the Distributive Property, we learned that providing a standardsbased learning environment facilitates and deepens student learning in that it promotes equity among students. In addition, observing student learning in real time and in the team reflecting for the purpose of monitoring and adjusting instruction is crucial in supporting students' learning. In collaborating with teachers in planning and reflecting, we analyzed student work and shared notes regarding teacher moves and student understanding. This research process resulted in implementation of collaborative professional development, improvement of instructional strategies, and increased student achievement. (TLC\#7)

In the Lesson Study written reports, the topic of equity appeared many times. Teachers were developing a lens to think about how their instructional moves empowered or supported each student as a learner, as well as how the classroom environment provided equitable learning opportunities.

One of our main focus areas in our lesson was equity. We planned the lesson to be equitable by introducing random calling upon students using index cards [each] with a students' name, encouraging paraphrasing, and routinely revisiting the learning targets and criteria for success in the math lesson. After reflection upon the first lesson, the team concluded that we could still make the lesson more equitable. For the second lesson we provided students with an entrance ticket before the lesson to reinforce vocabulary, encouraging pictorial representations and word definitions for each term. Students were engaged in the activity immediately and the vocabulary reinforcement allowed more students to actively participate in subsequent discussions using the appropriate vocabulary. Our revised research lesson also included making the problem more accessible through multiple entry points into the math task (low floor/high ceiling). The changes were small, yet so impactful - an insight that would not have been made without the lesson study process of deep reflection and collaboration with colleagues. (TLC\#8)

From my perspective, Lesson Study is about looking closely with a lens on student learning with colleagues who are learning together as professionals to become more proficient at teaching.
You go through disequilibrium and it can challenge you as a teacher. It is different from any other professional development in that it truly engages teachers in the process, uses reflection to focus on teacher practices and students' learning, and then follows through on the reflection by taking responsible actions to advance learning. Many experiences of professional development give you the information and say, "Now, have a go," and there is no application. For Lesson Study, you are forever changed through the teaching of that particular lesson, as well as those that follow. This is the reason that teachers would benefit the most from engaging in research and studying teaching practices through Lesson Study. (TLC\#9)

Lesson Study affords opportunities for investigating core elements of teaching. It is an active space for developing, and improving research lessons to examine the skills and instructional practices that support teachers and students' enjoyment and learning of mathematics.

A teacher leader reported the following after having worked with a team of colleagues in a Lesson Study cycle.

I have developed, reviewed, and taught lessons throughout my teaching career. After thoughtfully co-designing research lessons and studying the impact on students in my classroom, I realized the lessons we developed together focused squarely on supporting every student in the classroom to understand and make sense of the math. It has changed my behaviors, opened my eyes to how the choices and actions ... my understanding of mathematics and the teaching practices I use will shape students' lives and their views of learning mathematics. Every action matters, each choice, the teacher and student interactions in the classroom, every word can make a difference. It is powerful to understand teaching as the central vehicle responsible for students' learning. (TLC\#10)

One key theme that emerged in the LIFT teacher leader Lesson Study documentation was the value that teachers experienced in collaborating with peers through planning and teaching research lessons in their classrooms.

It is a really rare opportunity, unfortunately, to think about one question you have as a practitioner and explore it thoroughly, but when you have support (such as I have through LIFT) and time dedicated to thinking about that question, then amazing learning can happen with both the teacher and students. We are missing the mark in the U.S. We need to invest in teachers in order to invest in students (this is not about money, but time). (TLC\#11)

I learned that the infrastructure of schooling needs to change. When we have the TIME to work together as colleagues, we can accomplish so much more than working in isolation. . . I learned more 
from my fellow teachers and the experiences we have together in Lesson Study than I've ever learned through other professional development or conferences. (TLC\#12)

One of the major things that I carry forward with Lesson Study, as a process of focused research on practice, is the never-ending need for professional learning and that it is a life-long journey. We never know all there is to know about how students learn. It is our responsibility to constantly be reflecting on what is happening in the classroom with our students and work in a generative culture with colleagues to systematically research our instructional practices so we are able to improve math learning for all students. (TLC\#13)

As a group of teacher learners during the lesson study reflection piece, both after the first teach and the second teach, we were able to step back from the delivery of the lesson. We collectively discovered more areas of concern in the lesson than we could have on our own. We also were able to generate more solution possibilities to make the lesson richer. Our group could be more honest and critical about the lesson. No one of us was the expert, but instead, we were learning together. We were not judging any one teacher or being judged. This allowed for honest critique of our work.

The experience created an opportunity and an obligation to address such questions as:

1. What is the mathematics that we have planned for in the lesson?

2. Who is "getting it" and who is not and why?

3. How can we change the lesson to meet the needs of all students?

As a result of this reflective practice, I feel that it goes beyond a single lesson studied. It now has the potential to transform the approach to planning lessons that are of high quality and result in successful student learning for all students. (TLC\#14).

\section{Conclusions}

Lesson Study has provided opportunities for understanding the LIFT teacher leaders', mathematicians', and mathematics educators' beliefs and actions about teaching, developing mathematical knowledge and skills, and investigating students' mathematical thinking and reasoning. The teacher leaders' mathematical knowledge and skills have changed based on classroom observational data and written documentation of teacher leaders' perceptions of the Lesson Study process.

The project leaders have come to understand the potential of Lesson Study as a viable approach for instructional improvement in $\mathrm{K}-12$ classrooms. Teacher leaders have taken ownership of this schoolbased process as a useful way to advance their practices in mathematics classrooms through design- ing, testing, and refining mathematics lessons. They understand Lesson Study as a process for professional learning at school sites. Teacher leaders have requested an alternate, more compact version of Lesson Study. As a result, the LIFT project has developed and utilized a collaborative teaching and learning cycle that includes the key elements of the formal Japanese Lesson Study process [32] [34] but is more succinct and easily implemented in the school day. Several LIFT teacher leaders' schools are choosing this modified design of Lesson Study as a model for ongoing professional learning situated in mathematics classrooms. For LIFT, Lesson Study is a resource for university and $\mathrm{K}-12$ teacher leaders to integrate mathematics research and practice, build a collaborative culture for understanding mathematics more deeply, and create robust professional knowledge required for improving teaching to support students' learning.

\section{Acknowledgements}

This study was supported by National Science Foundation Grant \#0928867. Any conclusions stated here are those of the authors and do not necessarily reflect positions of the National Science Foundation.

\section{References}

[1] Darling-Hammond, L., \& Sykes, G. (Eds.). (1999). Teaching as the learning profession: A handbook of policy and practice. San Francisco, CA: Jossey-Bass.

[2] Loucks-Horsley, S., Love, N., Stiles, K. E., Mundry, S., $\&$ Hewson, P. W. (2009). Designing professional development for teachers or science and mathematics. Thousand Oaks, CA: Corvin.

[3] Putman, R. T., \& Borko, H. (2000). What do new views of knowledge and thinking have to say about research on teacher learning? Educational Researcher, 29(1), 4-15.

[4] Ball, D. L. (2003). Using content knowledge in teaching: What do teachers have to do, and therefore have to learn? Retrieved from http://sustainability2003.terc.edu/go.cfm/key_1

[5] Ball, D. L., \& Cohen, D. K. (1999). Developing practice, developing practitioners: Toward a practice-based theory of professional education. In L. Darling-Hammond \& G. Sykes (Eds.), Teaching as the learning profession: Handbook of policy and practice (pp. 3-32). San Francisco, CA: Jossey-Bass.

[6] Ball, D. L., Hill, H., \& Rowan, B. (2005). Effects of teachers' mathematical knowledge for teaching on student achievement. American Educational Research Journal, 42, 371-406.

[7] Shulman, L. (1986). Those who understand: Knowledge growth in teaching. Educational Researcher, 15(5), 4-14. 
[8] Creswell, J. W. (2003). Educational research: Planning, conducting, and evaluating quantitative and qualitative research. Upper Saddle River, NJ: Pearson.

[9] Tashakkori, A., \& Teddlie, C. (2003). Handbook of mixed methods in social and behavioral research. Thousand Oaks, CA: Sage.

[10] Cobb, P., Confrey, J., diSessa, A., Lehrer, R., \& Schauble, L. (2003). Design experiments in educational research. Educational Researcher, 32(1), 9-13.

[11] Ball, D. L., \& Forzani, F. M. (2011). Building a common core for learning to teach, and connecting professional learning to practice. American Educator, $35(2), 17-21,38-39$.

[12] Cohen, D. K., \& Ball, D. L. (2001). Making change: Instruction and its improvement. Phi Delta Kappan, 81, 73-77.

[13] Hiebert, J., Gallimore, R., Garnier, H., Givvin, K. B., Hollingsworth, H., Jacobs, J. C., ... Stigler, J. (2003). Teaching mathematics in seven countries: Results from the TIMSS 1999 Video Study. Washington, DC: U.S. Department of Education, National Center for Education Statistics.

[14] Stigler, J., \& Hiebert, J. (1999). The teaching gap: Best ideas from the world's teachers for improving education in the classroom. New York, NY: Free Press.

[15] Stigler, J., \& Hiebert, J. (2004). Improving mathematics teaching and learning. Educational Leadership, 61(5), 12-17.

[16] National Council of Teachers of Mathematics. (2000). Principles and standards for school mathematics. Reston, VA: Author.

[17] Smith, M. S. (2001). Practice-based professional development for teachers of mathematics. Reston, VA: National Council of Teachers of Mathematics.

[18] Weiss, I. R., Pasley, J. D., Smith, P. S., Banilower, E. R., \& Heck, D. J. (2003). Looking inside the classroom: A study of $K-12$ mathematics and science education in the United States. Retrieved from http://www.horizonresearch.com/insidetheclassroom/reports/looking/

[19] Dweck, C. S. (2006). Mindset. New York, NY: Random House.

[20] Hiebert, J., \& Morris, A. (2012). Teaching rather than teachers, as a path towards improving classroom teaching. Journal of Teacher Educator, 63, 92-102.

[21] Lampert, M., \& Graziani, F. (2009). Instructional activities as a tool for teachers and teacher educators' learning. Elementary School Journal, 109, 491-509.

[22]Wenger, E., McDermott, R., \& Snyder, W. (2002). Cultivating communities of practice. Boston, MA: Harvard Business School Press.

[23] Greeno, J., Moore, J., \& Smith, J. (1993). Transfer on trial: Intelligence, cognition, and instruction. Norwood, NJ: Ablex.
[24] Lewis, C. C. (2002). Lesson Study: A handbook of teacher-led instructional change. Philadelphia, PA: Research for Better Schools.

[25] Lave, J., \& Wenger, E. (1991). Situated learning: Legitimate peripheral participation. Cambridge, MA: Cambridge University Press.

[26] Ball, D. L., Sleep, L., Boerst, T., \& Bass, H. (2009). Combining the development of practice and the practice of development in teacher education. Elementary School Journal, 109, 458-474.

[27] Kinzer, C., \& Hord, S. (2009). Assessment for professional learning community development. In S. Hord, J. Roussin, \& W. Sommers (Eds.), Guiding professional learning communities: Inspiration, challenge, surprise and meaning (pp. 102-109). Thousand Oaks, CA: Corwin Press.

[28] Cochran-Smith, M., \& Lytle, S. L. (1999). Relationships of knowledge and practice: Teacher learning in communities. Review of Educational Research, 24, 249305 .

[29] Sparks, D. (2004, March). Taking action to bridge the knowing-doing gap. National Staff Development Council Results Newsletter, p. 2.

[30] Teaching Works. (2013). Great teachers aren't born, they're taught. Retrieved from http://www.teachingworks.org/

[31] Hiebert, J., Gallimore, R., \& Stigler, J. W. (2002). A knowledge base for the teaching profession: What would it look like and how can we get one? Educational Researcher, 31(5), 3-15.

[32] Takahashi, A., \& Yoshida, M. (2004). Ideas for establishing Lesson Study communities. Teaching Children Mathematics, 10, 436-443.

[33] Lewis, C. C., Perry, R. R., \& Hurd, J. (2009). Improving mathematics instruction through lesson study: A theoretical model and North American case. Journal of Mathematics Teacher Education, 12, 285-304. doi:10.1007/s10857-009-9102-7

[34] Yoshida, M. (2000, August). Framing Lesson Study for U.S. participants. Paper presented at the Studying Classroom Teaching as a Medium for Professional Development, Makuhari, Japan.

[35] Uribe-Flórez, L. J., Al-Rawashdeh, A., Morales, S., Hadfield, O. D., \& Kinzer, C. (under review). Training to use the observation of learning environment instrument in mathematics classroom.

[36] National Governors Association and Chief Council of State School Officers. (2010). Common Core State Standards in Mathematics. Washington, DC: Author.

[37] Leadership Institute for Teachers (LIFT). (2014). Annual report 2014: Project \# 0928867, submitted to the National Science Foundation. Washington, DC: Author. 